\title{
Breastfeeding Knowledge, Attitude, and Practice and Related Determinants Among Maternal in Gondar, Ethiopia: Cross-Sectional Study
}

\author{
Muluken Asfaw Admasu, Erika Cione \\ Department of Pharmacy and Health Sciences and Nutrition, Università Della Calabria, Cosenza, Italy \\ Email address: \\ mulukena@gmail.com (M. A. Admasu), erika.cione@unical.it (E. Cione)
}

\section{To cite this article:}

Muluken Asfaw Admasu, Erika Cione. Breastfeeding Knowledge, Attitude, and Practice and Related Determinants Among Maternal in Gondar, Ethiopia: Cross-Sectional Study. International Journal of Nutrition and Food Sciences. Vol. 5, No. 1, 2016, pp. 25-30. doi: 10.11648/j.ijnfs.20160501.14

\begin{abstract}
Breastfeeding has always been the ideal feeding practice for infants because of that it is one of the components of Primary Health Care and considered as natural practices in Ethiopia even though it remains a challenging due to lack of knowledge of mothers. The objective of this study was to assess the breastfeeding knowledge, attitude, practice and related Determinants among Maternal in Gondar; Northwest Ethiopia. A cross sectional community based study was carried out from September to December, 2015 in Gondar City. A total of 543 women who had a child aged less than 24 months from five different villages. The sample size determination was calculated using the single proportion formula. Households that have lactating mothers who had child less than 24 months were selected by multistage random sampling technique. The questionnaire was distributed according to the proportion of the selected village population Data were analyzed using SPSS v21. Binary logistic regressions were used to see the strength of association between independent and dependent variables using odds ratios and $95 \%$ of confidence intervals. Finally a multivariate logistic regression analysis was made to identify the predictors of maternal knowledge about optimal breastfeeding practices. Full breastfeeding was reported by $59.3 \%$, mixed feeding was reported by $31.3 \%$ and infant formula feeding was reported by $12.4 \%$. Almost one third of the full breastfeeding group did so for 7-12 months, and almost two thirds did continue breastfeeding for more than one year. Employed women were more likely not to practice full breastfeeding compared to unemployed women (odds ratio 3.34, 96\% CI 1.60, 6.98), and women who had caesarian delivery were more likely not to repetition full breastfeeding compared to those who had vaginal delivery (odds ratio 2.36, 97\% CI 1.17, 4.78). The women had a positive attitude but short maternity leaves had a negative impact on breastfeeding. This study showed that a majority of mothers has known the importance of Exclusive Breast Feeding and have good attitude, knowledge in order that strongly agree that Exclusive Breast Feeding is advantageous for infant aged less than six months. Though, poor practice to exclusive breastfeeding for the first six months postpartum among urban mothers. It is speculated health care providers and decision makers should be comprehensively addressed on adverse work related issues to improve exclusively breast feeding practices in the study community.
\end{abstract}

Keywords: Optimal, Exclusive Breast Feeding, Attitude, Knowledge, Practices, Factors, Gondar, Ethiopia

\section{Introduction}

Breastfeeding has always been the ideal feeding practice for infants. There is extensive evidence of short-term and long-term health benefits of breastfeeding for infants and mothers [1-4]. In addition to specific health advantages for infants and mothers, breastfeeding also benefits the society by reducing health care cost, parental employee absenteeism and associated loss of family income [5] after birth the health of the baby depends upon the nurturing practice adopted by the family. The ideal food for the young infant is human milk which has the specific characteristics that match the growing infants' nutritional requirements. Breastfeeding is a socially constructed and controlled practice. It is often presented as a natural practice. As a global goal for optimal maternal and child health and nutrition, all women should be enabled to practice exclusive breastfeeding, and all infants should be fed exclusively on breast milk, from birth to 6 month of age. [22] According to world health organization (WHO), breast milk 
has the complete nutritional requirements that a baby needs for health development. Furthermore, it is safe and contains anti bodies that help protect infants and boost immunity. Consequently, breast feeding contributes to reduced infant morbidity and mortality due to diarrhea, respiratory or ear infections and other infectious diseases. The WHO recommends that for the first six months of life, infants should be exclusively breast feed to achieve optimal growth, development and health. Thereafter, infants should receive nutritionally adequate and safe complementary foods, while continuing to breast for up to two years or more [9] the overall concepts of Primary Health Care and the implementation of the Ethiopian Health Extension Programmer, and find out about some of the successes that the country has achieved in improving the health service and the health of its communities. Ethiopia is dedicated to working towards the Millennium Development Goals (MDG) and this study will include some information about the way that the MDG health-related goals are being focused on. The 2011 Ethiopian DHS shows, 52 percent of children fewer than six months (aged 0-5 months) are exclusively breastfed $[11,13]$. In addition to breast milk, 19 percent of infants under six months are given plain water only, while 14 percent are given milk other than breast milk and 4 percent are given non-milk liquids and juice. Furthermore, 10 percent of infants fewer than six months are given complementary foods. By age 6-9 months, 51 percent of infants are given complementary foods. Sixteen percent of infants under six months are fed using a bottle with a nipple, a practice that is discouraged because of the risk of illness to the child [9]. This may be due to the barriers of translating the message of exclusive breast feeding into practice. Therefore, this study was designed to investigate the different aspect of lactating mothers of Gondar city to assess their knowledge, attitude and practice on exclusive breast feeding. In addition to that, this study also used to collect base line information about current knowledge, attitude and practice related to feeding of infants with special focus on exclusive breast feeding. The information generated from this study will be provided to the concerned bodies and can be useful for designing appropriate strategies for exclusive breast feeding [4, 10, 29].

\section{Materials and Methods}

A cross sectional community based study was carried out from September to December, 2015 in Gondar City. A total of 543 women who had a child aged less than 24 months from five different villages. The sample size determination was calculated using the single proportion formula. Households that have lactating mothers who had child less than 24 months were selected by multistage random sampling technique. The questionnaire was distributed according to the proportion of the selected village population Data were analyzed using SPSS v21. Binary logistic regressions were used to see the strength of association between independent and dependent variables using odds ratios and $95 \%$ of confidence intervals. Finally a multivariate logistic regression analysis was made to identify the predictors of maternal knowledge about optimal breastfeeding practices.

Gondar is the biggest and most populous city in Amhara Regional State, is located $750 \mathrm{~km}$ Northwest of Addis Ababa, the capital of Ethiopia. In Gondar, there are 21 kebeles (the smallest administrative units). Based on the 2007 National population census, the city has a total of 213,673 (104,769 male and 108,904 female) population. Out of these, 108,904 were females in the re-productive age groups (15-49 years). In the city, the expected number of pregnancies in a year is 7,843 with the expected live births of 7,483. Number of households in the city are 37,519 [19]. Number of households in the city are 37,519 The source population of this study was lactating mothers that currently resides in Gondar city and that have a child less than 24 months [19, 26].

The sample size determination was calculated using the single proportion formula. Households that have lactating mothers who had child less than 24 months were selected using a multistage random sampling technique. In the first stage, three out of 12 kebeles ( $25 \%$ of the total area) were selected by simple random sampling technique. In the second stage, a total of 543 households were selected using a systematic random sampling method. In this process samples were proportionally allocated to each selected kebeles. Total number of households was obtained from the respective administrative areas and used to calculate the sampling fraction the questionnaire was distributed according to the proportion of the selected village population. Data was collected with structured questionnaire that was adapted from standard questioners and relevant literature reviews by using face to face interview. Five percent of the questionnaire was pretested before data collection relevance and applicability of the questioners. The data collectors were trained on how to collect the data and conduct the interview.

Ethical clearance was obtained from research committee at University of Calabria and then data were collected after getting permission from Gondar city administration. Informed consent was read to the respondent before the interview. All information was kept private and confidential. All mothers were told about the purpose of study.

\section{Results and Conclusions}

\subsection{Demographic Characteristics}

In total 543 mothers who had children less than 24 months were successfully interviewed and participated in the study, yielding a response rate of $100 \%$. The majority $498(91.71 \%)$ mothers were in the age group of $\leq 30$ years (Table 1). 
Table 1. Socio-demographic characteristics of study participants.

\begin{tabular}{|c|c|c|}
\hline Variables & Number & Percent \\
\hline \multicolumn{3}{|c|}{ Age of mothers in year } \\
\hline$<30$ & 498 & 91.71 \\
\hline$>30$ & 45 & 8.29 \\
\hline \multicolumn{3}{|c|}{ Age of child in months } \\
\hline $0-6$ & 184 & 33.88 \\
\hline $7-12$ & 183 & 33.70 \\
\hline $13-24$ & 176 & 32.42 \\
\hline \multicolumn{3}{|l|}{ Sex of child } \\
\hline Mal & 245 & 45.12 \\
\hline Female & 298 & 54.88 \\
\hline \multicolumn{3}{|c|}{ Religion of others } \\
\hline Orthodox & 312 & 57.46 \\
\hline Muslim & 152 & 27.99 \\
\hline Protestant & 65 & 11.97 \\
\hline Others & 14 & 2.58 \\
\hline$<$ Grade4 & 59 & 10.86 \\
\hline Grade5-8 & 124 & 22.84 \\
\hline$>$ Grade 8 & 245 & 45.12 \\
\hline \multicolumn{3}{|c|}{ Maternal employment } \\
\hline Employed & 190 & 34.99 \\
\hline Unemployed* & 353 & 65.01 \\
\hline
\end{tabular}

*Mothers have no formal job; they are mostly self-employed subsistence farmers.

\subsection{Factors Influencing Breast Feeding}

All mothers in the study 532(97.8\%) were ever practiced breast feeding and were got health information about breast feeding. Their main source of information was health institutions 341(62.8\%), health institutions and mass media
$152(27.9 \%)$, books $45(8.29 \%)$ and others 5(0.92\%). From the total 543 mothers who were participated in the study, $229(42.17 \%)$ mothers had good health status with fertility determinants showed that 54(24.5\%) long birth interval greater than 04 years (Table 2).

Table 2. Influencing factors of breast feeding of respondents in study area.

\begin{tabular}{|c|c|c|}
\hline Variables & Number & Percent \\
\hline \multicolumn{3}{|c|}{ Have you ever practiced breast Feeding } \\
\hline Yes & 532 & 97.8 \\
\hline No & 11 & 2.02 \\
\hline \multicolumn{3}{|c|}{ Have you ever get any health information breastfeeding } \\
\hline Yes & 533 & 98.16 \\
\hline No & 10 & 1.84 \\
\hline \multicolumn{3}{|c|}{ If yes can you mention the sources of information } \\
\hline Books & 45 & 8.29 \\
\hline Health institution and media & 152 & 27.9 \\
\hline Other & 5 & 0.92 \\
\hline \multicolumn{3}{|c|}{ How you evaluate your general health status } \\
\hline Very good & 246 & 45.3 \\
\hline Good & 229 & 42.17 \\
\hline Bad & 35 & 6.44 \\
\hline $1-2$ Years & 108 & 19.89 \\
\hline 3 Years & 135 & 24.86 \\
\hline$>4$ Years & 162 & 29.83 \\
\hline Not applicable & 138 & 25.41 \\
\hline
\end{tabular}

\subsection{Knowledge of Respondents About Exclusive Breast Feeding}

Regarding women's knowledge, all mothers 543(100\%) knew the importance of breast feeding/EBF and 498(91.71\%) were reported breast milk alone is important for new born infant. 494(90.97\%) mothers reported frequent breast feeding needed for less than 6 months of infant and 245(45.12\%) mothers were reported between 6-8 times breast fed per day. From study participants, 192(87.3\%) had knowledge about 
EBF and 28(12.7\%) mothers hadn't the knowledge about EBF and were started complementary feeding before 4 months of age due to the reason they didn't think breast milk alone is sufficient for the baby $12(5.45 \%)$, their breast milk is not sufficient $10(4.55 \%), 6(2.73 \%)$ were due to work related problems. Of study subjects, only $136(61.8 \%)$ mothers had knowledge about the danger of bottle feeding and said that it is not safe for the child, it can cause child hood infections like diarrhea, vomiting, respiratory infections and other infectious diseases (Table 3).

Table 3. Knowledge of lactating mothers towards exclusive breastfeeding in study area.

\begin{tabular}{|c|c|c|}
\hline Variables & Number & Percent \\
\hline \multicolumn{3}{|l|}{ Do you know the importance of breast feeding } \\
\hline Yes & 543 & 100 \\
\hline No & 0 & 0.00 \\
\hline \multicolumn{3}{|c|}{ Which one of the following do you think is/ are important for the new born } \\
\hline Breast Milk only & 498 & 91.71 \\
\hline Breast milk with plain water & 29 & 5.34 \\
\hline Breast milk with Butter & 11 & 2.02 \\
\hline \multicolumn{3}{|l|}{ For how long should infant EBF only } \\
\hline$<4$ months & 11 & 2.02 \\
\hline 4-6 months & 494 & 90.97 \\
\hline$>6$ months & 38 & 6.99 \\
\hline \multicolumn{3}{|l|}{ Do you think breast feeding harms the child } \\
\hline No & 543 & 100 \\
\hline \multicolumn{3}{|l|}{ Do you think bottle feeding dangerous for the baby } \\
\hline No & 218 & 40.14 \\
\hline \multicolumn{3}{|l|}{ Did you start complementary feeding before 4 months of age } \\
\hline Yes & 58 & 10.68 \\
\hline No & 485 & 89.31 \\
\hline \multicolumn{3}{|l|}{ If yes what is your possible reason } \\
\hline MY breast milk is not sufficient & 22 & 4.05 \\
\hline I don't think as breast milk alone is sufficient for baby & 27 & 4.97 \\
\hline Other & 9 & 1.65 \\
\hline \multicolumn{3}{|c|}{ If the infant is less than 6 months how frequent he/she gets breast feeding } \\
\hline$<4$ times & 17 & 3.13 \\
\hline 4-5 times & 98 & 18.04 \\
\hline $6-8$ times & 245 & 45.12 \\
\hline$>8$ times & 183 & 33.70 \\
\hline
\end{tabular}

Table 4. Attitudes of lactating mothers towards exclusive breastfeeding in study area.

\begin{tabular}{lll}
\hline Variables & Number & Percent \\
\hline What do you prefer to feed your baby for the first 6 Months & & 714 \\
Breast milk alone & 54 & 76.24 \\
Breast milk with formula & 54 & 9.94 \\
Breast milk with cow milk & 11 & 9.94 \\
Others & & 2.05 \\
$\begin{array}{l}\text { Do you feel the EBF for 6 months infant has advantageous? } \\
\text { Agree }\end{array}$ & 483 & 60 \\
$\begin{array}{l}\text { Disagree } \\
\text { Do you believe that the first milk (colostrum) should be discarded? } \\
\text { Agree }\end{array}$ & 162 \\
$\begin{array}{l}\text { Neutral } \\
\text { Disagree } \\
\text { What is your opinion about EBF in the first } 6 \text { months? }\end{array}$ & 27 \\
It is useful and sufficient & 357 & 29.85 \\
\hline
\end{tabular}

\subsection{Attitudes of Respondents Towards Exclusive Breast Feeding}

Regarding the community's attitude towards breast feeding, majority of mothers $483(88.95 \%)$ had good attitude and strongly agree that the EBF is advantageous for infants aged less than 6 months. In contrary, 60(11.05\%) were disagree and had negative attitude on EBF. Furthermore, $165(29.83 \%)$ agree that colostrum should be discarded,
$357(65.74 \%)$ agree that colostrum should not be discarded and the rest $27(4.97 \%)$ were neutral. A large majority of mothers, $483(88.95 \%)$ were suggested that EBF is useful and sufficient for infants aged less than 6 months and 60(11.05\%) were forwarded their opinion that EBF is useful but not sufficient for infants aged less than 6 months. 202(91.9\%) mothers believed that the infant should be breast fed as frequently as he/she needs. $82(37.3 \%)$ mothers were considered bottle feeding is dangerous and should not be 
used at all. Majority of mothers in this study were familiar with concept of breast feeding, 214(97.3\%) had perception that breast feeding is natural and appropriate today, $4(1.82 \%)$ believed that it makes them old and $2(0.91 \%)$ were suggested breast feeding is outmoded (Table 4 ).

\subsection{Practice of Study Subjects Towards Exclusive Breast Feeding}

352(64.82\%) mothers were started breast feeding immediately after delivery, but $191(35.17 \%)$ were started breast feeding after few hours of delivery. The study have shown that $434(79.92 \%)$ practiced optimal breast feeding. Of this only $266(48.97 \%)$ mothers were exclusively breast fed their child. However, 109(20.07\%) were not practiced EBF.
They initiated pre lacteal feeding for their child such as $21(3.86 \%)$ plain water and $10(1.84 \%)$ butter in the first six months. Out of $109(20.07 \%)$ mothers who were not practiced optimal $\mathrm{BF} / \mathrm{EBF}, 10(1.84 \%)$ were preferred to feed their infant/young child by breast milk with formula, 50(22.7\%) breast milk with cow milk, 10(1.84\%) breast milk with other semi solid food staffs because of work related issues. About 423(77.90\%) mothers did give colostrum for their infants. But $120(22.09 \%)$ did not gave colostrum to their infants. The major reasons cited for not giving colostrum are believe that first milk is dirty like pus $81(14.91 \%)$, everybody says it should not be given $12(2.20 \%)$, and it had no white milk 27(4.97\%) (Table 5).

Table 5. Practice of lactating mothers towards exclusive breastfeeding.

\begin{tabular}{|c|c|c|}
\hline Variables & Number & Percent \\
\hline \multicolumn{3}{|c|}{ When did you start breast feeding After delivery? } \\
\hline Immediately & 352 & 64.82 \\
\hline After few hours & 191 & 35.17 \\
\hline \multicolumn{3}{|l|}{ Daily frequency of breast feeding } \\
\hline$<4$ times a day & 27 & 4.97 \\
\hline$>4$ times a day & 516 & 95.02 \\
\hline \multicolumn{3}{|l|}{ Do you breast feed your baby Exclusively? } \\
\hline Yes & 434 & 79.92 \\
\hline No & 109 & 20.07 \\
\hline \multicolumn{3}{|l|}{ If yes how long EBF? } \\
\hline 2 months & 21 & 3.86 \\
\hline 3 months & 22 & 4.05 \\
\hline 4 months & 125 & 23.01 \\
\hline$>4$ months & 266 & 48.97 \\
\hline \multicolumn{3}{|l|}{ Did you give colostrum to your Baby? } \\
\hline Yes & 423 & 77.90 \\
\hline No & 120 & 22.09 \\
\hline \multicolumn{3}{|c|}{ If your answer is no what is your Reason not giving colostrum? } \\
\hline It had no white milk & 27 & 4.97 \\
\hline First milk is dirty like pus & 81 & 14.91 \\
\hline Everybody say it is shouldn't be given & 12 & 2.20 \\
\hline \multicolumn{3}{|c|}{ What was the first nutrient given for The infant? } \\
\hline Plain water & 21 & 3.86 \\
\hline Breast milk & 512 & 94.29 \\
\hline Butter & 10 & 1.84 \\
\hline
\end{tabular}

\section{Results}

Full breastfeeding was described by $59.3 \%$, mixed feeding was described by $31.3 \%$ and infant formula feeding was described by $12.4 \%$. Almost one third of the full breastfeeding group did so for7-12 months, and almost two thirds did continue breastfeeding for more than one year. Employed women were more likely not to practice full breastfeeding compared to unemployed women (odds ratio 3.34, 96\% CI $1.60,6.98)$, and women who had caesarian delivery were more likely not to repetition full breastfeeding compared to those who had vaginal delivery (odds ratio $2.36,97 \%$ CI 1.17, 4.78).

\section{Conclusions}

This study showed that a majority of mothers has known the importance of Exclusive Breast Feeding and have good attitude, knowledge in order that strongly agree that Exclusive Breast Feeding is advantageous for infant aged less than six months. Though, poor practice to exclusive breastfeeding for the first six months postpartum among urban mothers. It is speculated health care providers and decision makers should be comprehensively addressed on adverse work related issues to improve exclusively breast feeding practices in the study community.

\section{Acknowledgement}

The authors wish to thank University of Calabria Department of Pharmacy and Health Sciences and Nutrition for technical support to conduct the Research work and Dr. Araya Mengistu from Gondar University who provided valuable comments and helped by editing the manuscript, Last but not least i would like to thank Engineer Ephraim Asfaw for orchestrate and helped with data collection. 


\section{References}

[1] Chua S, Arulkumaran S, Lim I, Selamat N, Ratnam SS. Influence of breastfeeding and nipple stimulation on postpartum uterine activity. Br J Obstet Gynaecol. 1994 Sep; 101 (9): 804-5.

[2] Dewey KG, Heinig MJ, Nommsen LA. Maternal weight-loss patterns duringn prolonged lactation. Am J Clin Nutr. 1993 Aug; 58 (2): 162-6.

[3] Breast cancer and breastfeeding: collaborative reanalysis of individual data from 47 epidemiological studies in 30 countries, including 50302 women with breast cancer and 96973 women without the disease. Lancet. 2002 Jul 20; 360 (9328): 187-95.

[4] Rosenblatt KA, Thomas DB. Lactation and the risk of epithelial ovarian cancer. The WHO Collaborative Study of Neoplasia and Steroid Contraceptives. Int J Epidemiol. 1993 Apr; 22 (2): 192-7.

[5] Ball TM, Bennett DM. The Economic Impact of Breastfeeding. Pediatric Clinics of North America. 2001; 48 (1): 253-62.

[6] World Health Organization, UNICEF. Global strategy for infant and young child feeding. Geneva: World Health Organization; 2003 [cited 2010 02/02]; Available http://www.unicef.org/progressforchildren/2007n6/index_415 11.htm.

[7] WHO. Indicators for assessing breastfeeding practices. Geneva: World Health Organization1991 Contract No.: (WHO/CDD/SER/91.14).

[8] Binns CW, Fraser ML, Lee AH, Scott J. Defining exclusive breastfeeding in Australia. J Paediatr Child Health. 2009 Apr; 45(4): 174-80.

[9] World Health Organization. Indicators for assessing infant and young child feeding practices. Washinton D. C., USA: World Health Organization2008.

[10] National Program of Action for Child Development in Ethiopia (1991-2000).

[11] National Program of Action for Child Development in Ethiopia (2001-2010). 81 Ministry of health of the people's Federal democratic republic of Ethiopia; 2001.

[12] Family Health Department National guideline on the prevention of Mother -to - child Transmission of HIV in Ethiopia, Ministry of Health, Addis Ababa, Ethiopia, November 2001.

[13] Family Health Department National Strategy for infant \& young child feeding Federal ministry of health, Ethiopia, April 2004.
[14] Nduati R., et al. Effects of breastfeeding and formula feeding on transmission of HIV-1: a randomized clinical trial. JAMA March 1 2000; 283(9): 1167-1174.

[15] UNAIDS. WHO, UNICEF, UNAIDS Statement on current status of WHO/UNAIDS/UNICEF Policy guidelines September 1999. Geneva.

[16] Kesela T., Kebede D. pattern of feeding of infants in Addis Ababa, Ethiopia. Ethiop. J. Health Dev. 1996; 10 (1): 57-65.

[17] Rogers, E. M. Communication strategies for Family Planning, Free press, USA. 1973

[18] Piotrow etal. Behavior change Model: knowledge Approval, Intention, practice and Advocacy in communication framework, JHU. Ccp. 1997

[19] CSA. Population and housing census of Ethiopia. Result for Amhara Region, November 1998 Vol. 2: 1-328.

[20] Asefa M., Drewette R., Hewison J. An Ethiopian birth cohort study: the study design, Ethiop. J. Health Dev. 2002; 16 (special Issue): p. 21-36.

[21] Tekle Silassie B. K. The status of breast feeding among mothers of children aged less than two years and implications for the occurrence of acute diarrhea, Jimma, Southwest of Ethiopia. (Unpublished thesis submitted to Department of Community Health, AAU) 2002.

[22] UNICEF. The States of the World's Children, Focus on Nutrition, Oxford University Press, 1998: p. 28.

[23] Semprini AE et al. 1995. The incidence of complications after cesarean section in 156 women. AIDS 9: 913917.

[24] Dewey KG, Brown KH. Update on Technical Issues Concerning Complementary Feeding of Young Children in Developing Countries and Implications for Intervention Programs. Food and Nutrition Bulletin. Washington, DC, USA: Pan American Health Organization. 2003: 24 (1): 5-28.

[25] Health System - Center for National Health Development in Ethiopia http://cnhde.ei.columbia.edu/healthsystem/

[26] Federal Democratic Republic of Ethiopia: Census Commission: Summary and statistical report of the 2007 population and housing census. Addis Ababa, Ethiopia; 2008.

[27] 54th World Health Assembly: Infant and Young Child Nutrition (Resolution WHA54.2). Geneva: World Health Organization; 2001.

[28] Ulak M, Chandyo RK, Mellander L, Shrestha PS, Strand TA: Infant feeding practices in Bhaktapur, Nepal: a crosssectional, health facility based sur-vey. Int Breastfeed J 2012, 7: 1 .

[29] Lauer JA, Betrán AP, Victora CG, de Onís M, Barros AJD: Breast feeding patterns and exposure to suboptimal breastfeeding among children in developing countries: review and analysis of national. 